\title{
From the library
}

\section{Remembrance of things past} Jacques Lacan's first presentation of a patient was made to the Société neurologique on November 4, 1926, under the direction of the great neurologist Théophile Alajouanine, a friend of Edouard Pichon and a member of Action française. The case was one of fixed gaze caused by hypertonicity, together with extrapyramidal syndrome and pseudobulbar disorders of the spinal cord. It was an ordinary enough story concerning an unfortunate man of 65 who was taken ill while riding his bicycle and hospitalized at the Salpétriére. He had a fixed stare and a respiratory tic, and the furrow between the nose and the chin was deeper on the left side of the face than on the right. When the patient bent his knees to sit, he remained poised for a moment above the chair before falling down on to the seat. Lacan's clinical comments were lengthy, detailed, strictly technical, and devoid of emotion: an arid bit of ordinary hospital routine. (Elizabeth Roudinesco. Facques Lacan. New York: Columbia University Press, 1997:16-17.)

\section{Does a diet of fruit and vegetables} reduce the risk of breast cancer?

The association between fruit and vegetable consumption and the risk of breast cancer has been examined in at least 25 case controlled studies and a few cohort studies. A recent summary of 19 case control and three cohort studies concluded that elevated fruit and vegetable consumption probably reduces breast cancer risk. This pooled analysis of cohort study examined eight prospective studies with at least 200 incident breast cancer cases. These pooled results suggest that fruit and vegetable consumption during adulthood is not significantly associated with a reduced breast cancer risk. ( $(F A M A$ 2001;285:769-76.)

Can gene therapy treat chronic pain? Almost $60 \%$ of hospitalised people experience severe acute pain; $90 \%$ of patients with advanced cancer report pain that is often chronic and poorly managed. Even when pharmacological agents are administered correctly many simply fail to do the job. Recent advances in gene therapy suggest that alternative methods of treatment of pain may be available. Gene therapy might allow the insertion of a therapeutic gene, which would code for an antinociceptive receptor. Alternatively, a virus might be used to transfer antinociceptive receptors or neurotransmitters into a nerve cell along the pain conduction pathway involved. Further studies may bring this type of therapy to the clinic soon. (American Scientist 2001;89:126-35.)

Can a topical lotion prevent skin cancer? Every year approximately 1.3 million Americans are diagnosed with basal or squamous cell carcinoma. The sun's ultraviolet light is the main factor in causing genetic mutations in skin cells leading to skin cancer. Now a lotion containing liposomes filled with a viral DNA enzyme called $\mathrm{T} 4$ endonuclease $\mathrm{V}$ has been shown to repair skin damage. In 30 patients with xeroderma pigmentosum, the use of this lotion decreased the incidence of basal cell carcinoma by approximately one third. Studies of patients with recurrent squamous cell carcinoma are under way. ( $\mathrm{Sci}$ entific American 2001;March:21.)

Does the amount of sodium in your diet change your risk for hypertension?

The effect of dietary composition on blood pressure is a subject of major public health importance. Controversy surrounds the question of whether dietary sodium intake is related to hypertension. In this controlled prospective study 412 participants were randomly assigned to eat either a controlled diet with high, intermediate, or low levels of sodium for 30 consecutive days. Thus, compared with a controlled diet a high sodium level diet produced an elevation of systolic blood pressure of $7 \mathrm{~mm} \mathrm{Hg}$ in those patients without hypertension and $11^{1 / 2} \mathrm{~mm} \mathrm{Hg}$ elevation in participants with hypertension. This suggests that reduction of sodium intake levels below the recommendation of $100 \mathrm{mmol}$ pe day would result in substantial lowering of blood pressure in the general public. (New England Fournal of Medicine 2001;344:3-10.

\section{Oestrogen replacement in} post-menopausal women and the risk of myocardial infarction

For some years recommendations about the use of hormonal replacement therapy in post-menopausal women has been based primarily on observational studies which sugges that hormonal replacement therapy reduces the risk of coronary artery disease. In a study of 232 post-menopausal women who had a non-fatal myocardial infarction results sugges that among hypertensive women the association of hormonal replacement use and myocardial infarction risk differed from those with and without the prothrombin $20210 \mathrm{G} \rightarrow \mathrm{A}$ variant. If these findings are confirmed by additional studies, screening for this prothrombin variant may provide information as to which post-menopausal patients will benefit most from hormonal therapy. ( $F A M A$ 2001;285:906-13.)

\section{Spices: more than tasty}

Recent studies suggest that adding spices to our foods does more than simply improve their taste. Antimicrobial activity has been demonstrated in most spices with the greatest activity being exhibited in onions, garlic, thyme, and allspice. In fact, these four most potent spices killed every bacterial species tested in these studies. Bacteria tested are widely distributed and frequently implicated in foodborne illnesses. Bacteria studied included Clostridium botulinum, Escherichia coli Salmonella pullorum, Staphylococcus aureus, and Streptococcus faecalis. (American Scientist 2001;89:142-51.)

\section{Umbilical cords give lifeline to stroke patients}

Investigators in Florida have demonstrated that blood taken from umbilical cords may provide an excellent source of stem cells to treat patients who have suffered from a stroke. These stem cells can be prompted by growth factors to become immature nerve cells. When injected intravenously into rats that had suffered from strokes, results were encouraging. Within 2 weeks treated rats performed almost as well as rats who were entirely healthy. Although stem cells can be obtained from bone marrow cells these investigators suggest that the cells obtained from umbilical cords are less likely to provoke an immune response in the patient. (New Scientist 2001;2279:9.)

\section{Treating HIV by making infected cells} commit suicide

Investigators in Japan have shown that genetically engineered HIV can be used to set a "booby trap" in the immune cells that are the target of the virus. If these immune cells are then infected by the wild virus they will commit suicide preventing the virus from spreading. The suicide gene is called HSV-TK. This codes for an enzyme that turns an inactive prodrug ganciclovir into a highly toxic form. Researchers have shown that their technique can prevent wild HIV spreading among human immune cells grown in tissue culture. A preclinical study in mice carrying human immune cells is under way. (Human Gene Therapy 2001;12:227-31.)

\section{Incidence of dementia and Alzheimer's} disease in two communities

Considerable variations have been reported in the prevalence and incidence of Alzheimer's disease between countries, but most investigators have concluded that these variations are mainly the result of study design. This study is the first to report an incidence difference for dementia and Alzheimer's disease in two population studies from non-industrialised and industrialised countries using identical methods and the same group of investigators in both sites. In this study the incidence for Alzheimer's disease among African American living in Indianapolis, Indiana, is $2 \frac{1}{2}$ to 3 times the rate of Youba people living in Ibadan, Nigeria. These results suggest that Alzheimer's disease comes about as the result of an interplay between genetic predisposing factors and environmental ones. ( $F A M A$ 2001;285:739-47.)

\section{Do contact allergies in coronary stent} patients cause secondary restenosis? US vice president's Cheney's problems with his coronary stent procedures has highlighted the high incidence of reocclusion of coronary arteries in the area of previous stent procedures. In this study patients with an allergic patch test reaction to nickel and molybdenum had a higher frequency of in-stent restenosis than patients without hypersensitivity. This suggests that allergic reactions to the materials that make up the stents may be one of the triggering mechanisms for in-stent restenosis. (Lancet 2000;356:1895-7.) 